\title{
Pulse Wave Velocity
}

National Cancer Institute

\section{Source}

National Cancer Institute. Pulse Wave Velocity. NCI Thesaurus. Code C122087.

The rate at which a pressure wave moves distally through an artery, which is a direct measure of arterial stiffness. Clinically, this value is calculated by placing two pressure catheters a known distance apart (pulse wave distance), measuring the pressure wave's travel time between sensors (pulse transit time), and then dividing the distance by the transit time. 